\title{
Using social media to share the wonders of crystallography - perspectives from a structural database
}

\author{
llaria Gimondi, Yinka Olatunji-Ojo, Zainab Abdulali, Ana Machado, Sophie Bryant, Suzanna Ward \\ Cambridge Crystallographic Data Centre, Cambridge, United Kingdom \\ igimondi@ccdc.cam.ac.uk
}

Social media has the power to change people's lives, from what we wear and eat, to where we go and who we socialise with. How can we leverage this influence to help inspire a new generation of scientists and crystallographers?

At the Cambridge Crystallographic Data Centre (CCDC) we are involved in several projects to demonstrate the power of structural data in fun and engaging ways on social media. Over the last year we have created games and content targeted at inspiring a new generation of scientists. This has included a wide variety of activities and social media campaigns and is often done in conjunction with people in our community.

This talk will highlight some of these efforts and explore what we have learnt along the way. We will demonstrate how we have used social media to enable people to play fun educational card games, to share instructional videos and playlists, to share educational tips (\#CSDTopTipTuesday) and to encourage good data sharing practices.

We will conclude by summarising what we have learnt along the way and explore how we can better help others to spread the science of crystallography and its application as far as possible inside and outside the crystallographic community.

Keywords: database, education, CSD, communication 